\title{
De biofilms y otras películas
}

\section{Resumen}

\author{
Patricia M. Valdespino, Martín Merino, \\ Victor M. Valdespino y Silvia Batista
}

El conocimiento del mundo microbiano cada día crece, sorprendiéndonos y cuestionando los paradigmas de la Biología y la Química. Contrario a lo que solemos pensar, los microbios no viven solos sino en asociación con otros, formando en ocasiones capas tan delgadas como la punta de una aguja. Estas delgadas biopelículas están por todas partes y sus componentes son microscópicos, casi invisibles. Su estructura, diversidad y funciones son tan diversas como desconocidas; es decir, el conocimiento de las biopelículas apenas ha comenzado. Aquí hacemos un recuento de lo que estamos descubriendo y de lo que se vislumbra que está por descubrirse si estudiamos estas películas. Investigaciones recientes han revelado que las biopelículas juegan papeles clave en el equilibrio de los sistemas biológicos, por ejemplo, en los mecanismos de salud-enfermedad, ya que los causantes de las infecciones son biopelículas y no bacterias solitarias, como solíamos pensar. Es hasta ahora que empezamos a contar con los instrumentos y métodos necesarios para saber cuáles microbios están involucrados y qué composición química tienen las películas "babosas" que cubren alimentos y materiales. La participación de los microbios en las biopelículas es un tema creciente que impactará el desarrollo tecnológico en áreas como la biorremediación, la producción de energía y la terraformación o colonización de hábitats inhóspitos.

Palabras clave: biopelículas, microbioma, diversidad microbiana, biología de sistemas, salud enfermedad, biotecnología.

\section{ON BIOFILMS AND OTHER FILMS}

\section{Abstract}

Our knowledge of the microbial world is growing every day, surprising us and challenging the paradigms of Biology and Chemistry. Microbes do not live naturally isolated, but in association with other microbes, often forming films thin as a needle tip. These biofilms are everywhere, but they are microscopic and, therefore, practically invisible. Their structure, variety and functions are as diverse as they are unknown, since we have only begun to understand them. Here, we present an overview of the recent discoveries and promising new ones on biofilm research. Biofilms play key roles in the mechanisms that control health and disease in humans and in ecosystems' equilibrium. It is only lately that we are beginning to have the instruments and techniques required to identify the type of microbes involved in each biofilm and to understand the chemistry of the slimy films that cover food and other materials. The role of microbes in these biofilms is a growing research area that will impact the future of technological development in areas such as bioremediation, energy production and colonization of extreme environments (such as terraformation).

Keywords: biofilms, microbiome, microbial diversity, systems biology, health-disease, biotechnology.

Dol: http://doi.org/10.22201/codeic.16076079e.2019.v20n5.a1 


\section{Patricia M. Valdespino}

pancronica@gmail.com

http://orcid.org/0000-0002-2998-4627

http://www.researcherid.com/rid/M-2413-2018

Investigadora posdoctoral en el Lawrence Berkeley National Laboratory. Especialista tanto en metodologías clásicas como de nueva generación en ensambles microbianos biodiversos como modelo de estudio, para entender transformaciones biogeoquímicas, los flujos de los elementos biogeoquímicos principales y elementos de transición. Investiga el papel de los microbios en la formación de minerales y forma parte del Berkeley Synchrotron Infrared Structural Biology Imaging Program, donde se utiliza tecnología de última generación para explorar las interacciones químicas de los microbios a micro y nano escala. Además, en colaboración estrecha con grupos de investigación en Argentina y Uruguay, estudia la ecología molecular de organismos antárticos, la diversidad metabólica y las respuestas de los organismos al cambio ambiental.

\section{Martín Merino}

mmerino@cmarl.unam.mx http://orcid.org/0000-0002-6690-3101

Investigador Titular en el Instituto de Ciencias del Mar y Limnología de la Universidad Nacional Autónoma de México (UNAM) y miembro del Sistema Nacional de Investigadores (SNI) nivel 3.

Su principal interés es la Biogeoquímica Acuática, e intenta aplicar una visión trans-sistémica, para aprender de los contrastes y similitudes entre distintos ecosistemas. Ha publicado en revistas internacionales especializadas y ha acumulado a la fecha más de 1,600 citas.

\section{Victor M. Valdespino}

waldespinog@yahoo.com.mx

Médico especialista en Oncología y doctor en ciencias. Su área de interés es la Oncología traslacional humana, particularmente en las alteraciones moleculares que se presentan en diversos cánceres. Ha publicado en revistas internacionales especializadas además de diversos libros para nivel medio y medio superior.

\section{Silvia Batista}

silvia@iibce.edu.uy http://orcid.org/0000-0002-8702-6566

Profesora Adjunta de Investigación Grado 3, MEC, Instituto de Investigaciones Biológicas Clemente Estable, Uruguay. Su investigación en Microbiología molecular se centra en la bioquímica aplicada a la producción de biomateriales. Ha publicado en revistas internacionales especializadas. 
Hoy en día la biopelículas se usan para diversos procesos como el tratamiento de aguas residuales (González-Brambila et al., 2008) o la producción de biocombustibles (Ozkan et al., 2012). Los biofilms también son un factor clave en los mecanismos de salud-enfermedad, por lo que entender sus impactos nos llevará a rediseñar los tratamientos médicos, ya que anteriormente éstos se basaban en contener a un solo microorganismo patógeno (Morones Ramírez, 2009; Meza-Villezcas et al., 2019; UAEH 2019).

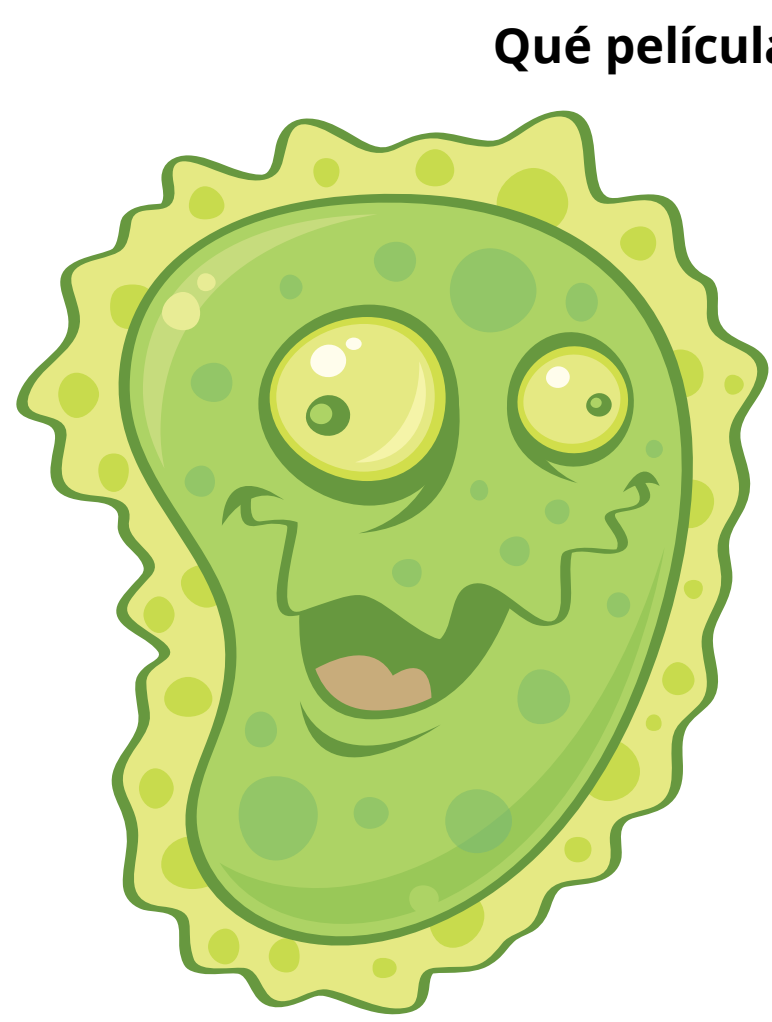

¿Alguna vez has tomado del refrigerador algún alimento, por ejemplo, un pedazo de carne o de pescado que huele muy extraño y se siente baboso? ¡Sí! Como bien lo intuyes, esa capa superficial o película que te parece resbalosa al tacto y que tiene un olor característico (que puede ocasionarte ganas de vomitar) es una biopelícula. Se trata de asociaciones muy complejas y diversas de microbios (bacterias, arqueas, virus y hongos). Pero no te asustes demasiado: no todo lo que tenga que ver con microbios es malo. Recuerda que hay ciertos productos muy necesarios en nuestra dieta que conllevan ingeniería microbiana, como el yogurt, los quesos, los alimentos fermentados, etcétera. Estos productos y sus microbios han acompañado la salud de los humanos desde tiempos milenarios.

Eso sí, como en todas las relaciones, es necesario escuchar y entender para tener una buena convivencia con las biopelículas. De hecho, cotidianamente nos deshacemos de muchas que están en los alimentos simplemente con agua y jabón o con desinfectantes basados en plata coloidal o compuestos clorados; lo cual puede salvarte de una gastroenteritis. Pero hay otras biopelículas que debes cuidar cotidianamente, pues, jte acompañarán toda la vida! Por ejemplo, la biopelícula de la cavidad oral, o las que están asociadas a las mucosas genital y nasal. Es sorprendente que, aunque las biopelículas son genéricamente similares entre personas, en detalle, su composición es única y además cambia con el tiempo. En resumen: ¡no hay dos películas iguales!

\section{¿De qué trata esta película?}

Una gran dificultad para estudiar los microbios y su microambiente es que la mayoría de ellos se desarrollan en agrupaciones biodiversas y son organismos invisibles a nuestra vista. Aún con un microscopio con buena resolución, la mayoría de los microbios son muy similares a simple vista y no podemos distinguirlos por su apariencia (ver figura 1). Gracias a novedosos desarrollos 
Figura 1. De arriba hacia abajo se muestra la secuencia de la formación de una biopelícula sobre una superficie. Células dispersas se van agregando, embebidas en una matriz polimérica (o EPS) y forman una biopelícula sobre una superficie. En un microscopio normal es difícil distinguir diferencias entre las distintas especies de microorganismos que componen la biopelícula. tecnológicos e instrumentos recientes, ahora estamos empezando a conocer en detalle la identidad de los "actores microbianos" y la composición química de las biopelículas. ¡Ésta es una era muy emocionante para estudiar los microbios! Así, la secuenciación de nueva generación permite hoy en día entender la identidad y la abundancia de microorganismos en muestras ambientales a partir de su señal genética. De manera similar, novedosos tipos de microscopía acoplada al análisis químico por imagen son también herramientas esenciales para entender de qué tratan estas películas (incluyendo su composición elemental y los factores que las favorecen).

A simple vista, es fácil confundir las biopelículas con otros materiales. Por ejemplo, la baba del nopal, el gel del Aloevera o el sustancioso caldo de tu abuelita no son productos microbianos, aunque lo parezcan porque tienen una consistencia gelatinosa similar a la de las biopelículas. Esta consistencia resbaladiza o babosa se debe a un componente esencial, al que damos un nombre tan poco específico como Sustancias Poliméricas Extracelulares (EPs por sus siglas en inglés, Extracellular Polymeric Substances). Las EPS son una colección de polímeros (cadenas largas que se forman por la unión de varias subunidades elementales, como las cuentas de un collar), construidos a base de ácidos orgánicos, carbohidratos, proteínas o ácidos nucleicos, entre otros (ver figura 1). Esta mezcla de sustancias constituye en sí misma un microambiente con condiciones apropiadas de humedad, acidez, nutrientes, movilidad, etcétera, para que los microbios realicen sus funciones (como individuos y como comunidad). El grosor de las EPS puede ser tan delgado como decenas de nanómetros hasta centímetros (1 nanómetro equivale a una diez millonésima de un centímetro).

\section{Formación de una biopelícula}
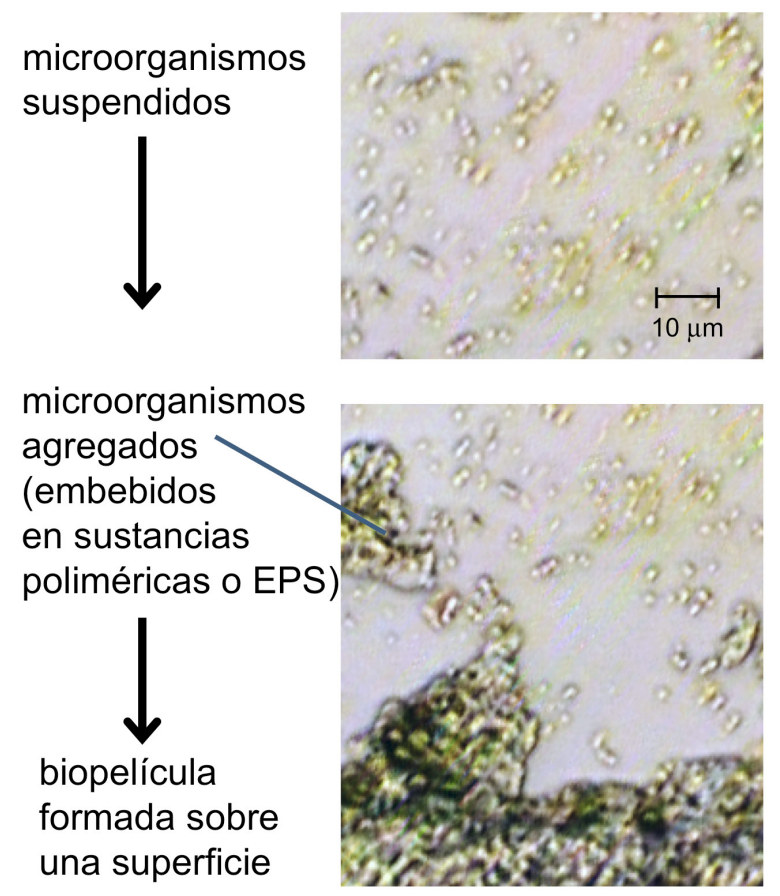


\section{Si hay nicho hay bicho}

El ambiente dentro de la biopelícula no sólo es diferente a nuestro entorno, sino que además cambia drásticamente; ¿puedes imaginar la existencia de condiciones muy diferentes de humedad, de oxígeno o de acidez/alcalinidad en una capa tan delgada? Si hacemos un acercamiento a una biopelícula que crece en el margen de un río veríamos que su superficie está expuesta a la luz del sol, al flujo del agua, al oxígeno atmosférico. Esta parte de la película es un ambiente propicio para hacer fotosíntesis (fabricar moléculas orgánicas usando luz y $\mathrm{CO}_{2}$ ). Indudablemente, aquí hay microorganismos fotosintetizadores, capaces de explotar en particular este nicho ecológico (el nicho comprende el microambiente y - a la vez - el rol del organismo que lo puede habitar). Aunque parezca difícil de imaginar, los microorganismos que crecen algo más abajo dentro de la biopelícula se encuentran ya en un ambiente muy distinto, donde, por ejemplo, la luz y el oxígeno ya no están disponibles. Este sería un nicho adecuado para microbios que utilizan para su desarrollo rutas metabólicas que no dependen del oxígeno, como las bacterias fermentadoras. En resumen, como podrás imaginar, la diversidad microambiental coincide con la diversidad biológica (número y tipo de microorganismos) de cada biofilm. Esto tiene implicaciones en su sobrevivencia y la resistencia al cambio ambiental.

\section{Películas buenas y películas malas}

Cualquier pequeño sabe que debe lavarse las manos antes de comer porque están llenas de bacterias y jeso es muy malo! Ese contacto infantil con el mundo microbiano ha marcado nuestra interacción con éste y naturalmente hemos percibido a los microorganismos como los "malos de la película", como agentes de enfermedades. Ahora que comenzamos a entenderlos con mayor claridad, sabemos que hay un inmenso mundo microbiano en el ambiente y que algunos de estos microorganismos realizan funciones muy importantes para los ecosistemas, y en general para todas las plantas y los animales (por ejemplo, el microbioma dentro de nosotros). Algunas bacterias son los personajes "buenos" que nos ayudan a vivir; por ejemplo, las bacterias fermentadoras Lactobacillus rhamnosus, Lactobacillus reuteri o Lactobacillus acidophilus, que ya están disponibles comercialmente (como probióticos) y que son auxiliares en trastornos digestivos, del tracto genital-urinario, de la piel, etcétera.

Efectivamente, hay biopelículas "de terror" (como las que crecen en el pollo o en el pescado que tienen muchos meses en el refrigerador), pero hay también biopelículas "buenas", como los biofilms microbianos en la boca que nos ayudan a procesar los alimentos y defendernos de bacterias patógenas. Cuando visites los márgenes de ríos y lagos, observa las biopelículas verdes o pardas que allí existen, las forman los "productores primarios" (organismos fotosintéticos, el primer eslabón de las redes alimenticias en los ecosistemas). Estas biopelículas pueden también fijar el nitrógeno atmosférico en forma de biomasa o contribuir a degradar contaminantes (como hidrocarburos); asimismo, son importantes 
para el ecosistema, pero son muy resbalosas, así que iprocura no pisarlas porque puedes caerte!

Como siempre ocurre en la naturaleza, que tan "buenos" o que tan "malos" son los microbios depende de equilibrios muy sensibles entre el anfitrión y el huésped. ¿Recuerdas el caso de los mineros chilenos que quedaron atrapados en una mina por 70 días? Cuand o felizmente los rescataron, uno de los principales problemas de salud que presentaron fue una alteración terrible en la salud de la boca. Y es que ahí viven en cada uno de nosotros de cientos a miles de millones de microorganismos — de más de 600 tipos diferentes-, que nos ayudan a procesar los alimentos (y todas las partículas que entran al organismo por ella (ver Luyo, 2005). La salud de la cavidad oral implica tener una higiene frecuente, pero bajo ciertas circunstancias se pueden alterar las condiciones microambientales del cuerpo y de la boca. Por ejemplo, cuando nos deshidratamos, nos exponemos a fuertes dosis de radiación solar, estamos muy estresados o en tratamiento médico, cuando nos lavamos los dientes excesivamente o cuando nos ocurren accidentes agradables como intercambiar un beso, puede haber consecuencias desde imperceptibles o leves (como inflamación de las encías, manchas o caries en los dientes) hasta alteraciones más graves que pueden implicar lesiones por virus o infecciones (ver Luyo, 2005).

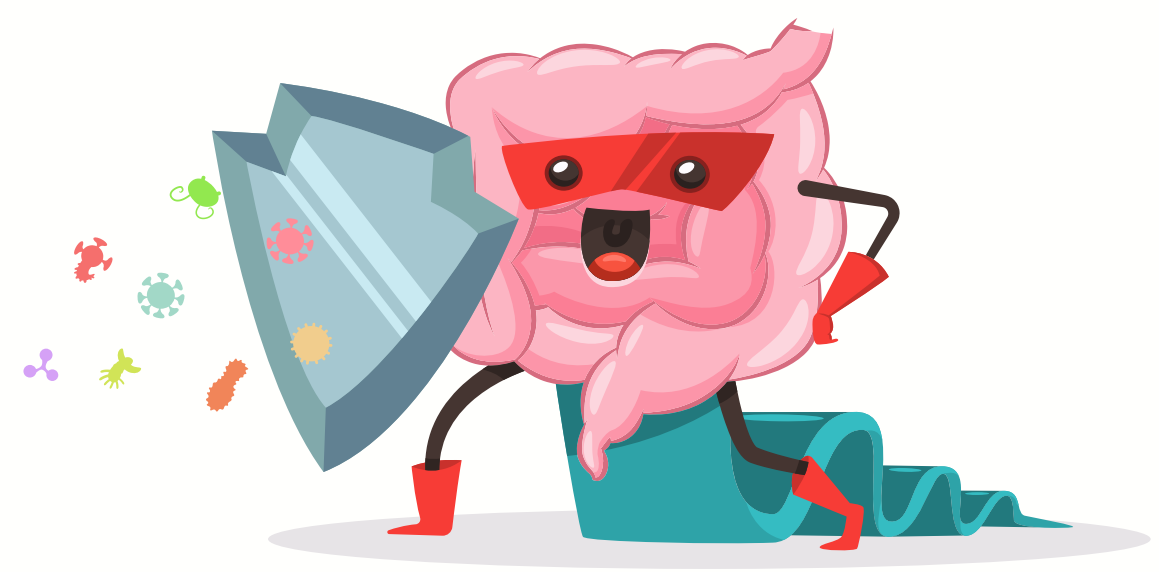

\section{Películas del futuro}

Las biopelículas microbianas están actualmente inspirando historias de ciencia ficción y experimentos científicos, ya que diversos procesos o compuestos generados en ellas pueden ser aprovechados en la industria del futuro. Mencionaremos dos casos solo para darte una idea de qué tan diversas pueden ser las aplicaciones de estas delgadas biomáquinas. 
1. Las biopelículas son estudiadas y usadas como filtros de contaminantes para sanear el agua de drenajes y de residuos de la agricultura. Ciertos microbios son capaces de transformar aguas contaminadas y llenas de nutrientes en aguas claras y útiles (González-Brambila y López-Isunza, 2008).

2. La especie humana ya está buscando colonizar otros astros como consecuencia del deterioro ambiental que estamos provocando en nuestro planeta. A la fecha consideramos que los actores más poderosos para cambiar los ambientes extraterrestres de hostiles a habitables son los microbios, en especial aquellos asociados a biopelículas, que serán participantes claves en estos procesos denominados terraformación. Ya se ejecutan a bordo de la Estación Espacial Internacional múltiples experimentos buscando las características y estrategias que permitan a los microbios vivir en condiciones de baja presión, baja temperatura, limitación de nutrientes o microgravedad (Qin et al., 2018; NASA News, 2019).

\section{Actores secundarios}

Como sucede en las películas, algunas veces los actores secundarios se roban la escena; en este caso, los organismos más pequeños o que no conocemos bien pueden tener una relevancia brutal y definir el éxito de toda la biopelícula. Un ejemplo muy claro son los microbios que habitan las zonas polares. Allí, los microorganismos se asocian y se recubren con una película que ellos mismos producen, la cual les permite sobrevivir en condiciones extremas de baja temperatura, alta radiación ultravioleta y ciclos de congelamientodescongelamiento. Algunas bacterias pueden producir polímeros, parecidos a plásticos, pero de origen microbiano, que son materiales muy resistentes que permiten a los microbios sobrevivir en estos ambientes crueles. También se ha detectado que algunos de estos microbios pueden degradar moléculas que son tóxicas o difíciles de procesar para la mayoría de los organismos, como los hidrocarburos (Ruberto et al., 2009).

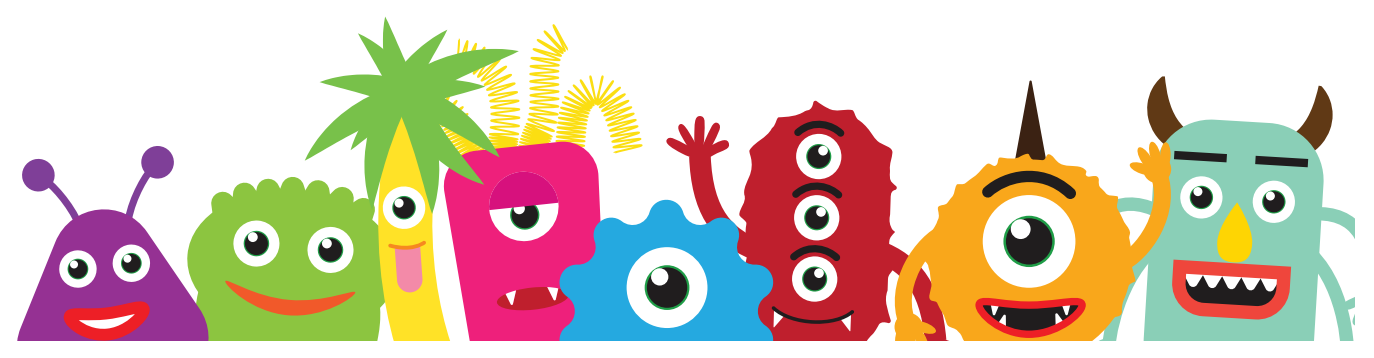




\section{Conclusiones}

Son los conjuntos de microbios asociados, que frecuentemente forman biopelículas, los que regulan los equilibrios de los sistemas naturales o las infecciones de plantas y animales (no se trata de microorganismos individuales). El entendimiento de las interacciones microbianas en estas películas, así como la interacción con su entorno, serán fundamentales en las siguientes décadas para beneficio de la humanidad y de los sistemas naturales.

Quizá en este punto ya estarás convencido de que este mundo "invisible a nuestros ojos" tiene repercusiones muy importantes para nuestra vida y para nuestro planeta. Para conocer más, acércate a las exposiciones, museos y recursos digitales dedicados al mundo microbiano, por ejemplo, Comicbacterias. Pero si no tienes tanto tiempo para salir a buscarlas, puedes también ponerte unos guantes, buscar una lupa y explorar el moho en tu bañera o tu charco más cercano, seguro te sorprenderás. ¡Ah, y no olvides buscar ese pedazo de queso que tienes olvidado en tu nevera!

\section{Referencias}

* Gallego, A. [direccióny producción] (18 de septiembre, 2018). Matilde, la holobionte. El bosque interior. Podcast recuperado de: http://www.rtve.es/alacarta/audios/elbosque-interior/bosque-interior-matilde-holobionte-18-09-18/4743224/.

* González-Brambila, M. y López-Isunza, F. (2008). Membrane-attached biofilm reactor under different flow rate conditions in the treatment of a synthetic wastewater. Revista Mexicana de Ingeniería Química, 7(3), 183-193.

* iTunes u-UAEH. (2019). Bacterias Formadoras de Biofilm [video]. Recuperado de: https://youtu.be/U7IQQSHL80Q.

* Luyo, A. G. P. (2005) La biopelícula: una nueva visión de la placa dental. Revista Estomatológica Herediana, 15(1), 82-85. Recuperado de: http://www.redalyc.org/ articulo.oa?id=421539343016.

* McGraw-Hill Animations. (6 de junio de 2017) Biofilms formation [video]. Recuperado de: https://youtu.be/ZYG5LzgQ-s8.

* Meza-Villezcas A., Gallego-Hernández A. L., Yildiz F. H., Jaime-Acuña O. E., RaymondHerrera O. y Huerta-Saquero A. (2019). Effect of antimicrobial nanocomposites on Vibrio cholerae lifestyles: Pellicle biofilm, planktonic and surface-attached biofilm. PLoS One, 14(6): e0217869. Dol: https://doi.org/10.1371/journal.pone.0217869.

* Morones Ramírez, R. (2017). El uso de la Plata en los antibióticos del futuro. Revista Digital Universitaria, 10, núm. 10, octubre. http://www.revista.unam.mx/ vol.10/num10/art69/art69.pdf.

* NASA News. (2018). Recuperado de: https://www.nasa.gov/mission pages/station/ research/news/microorganisms.html. 
- Ozkan, A., Kinney, K., Katz, L., \& Berberoglu, H. (2012). Reduction of water and energy requirement of algae cultivation using an algae biofilm photobioreactor. Bioresource technology, 114, 542-548. Dol: https://doi.org/10.1016/j.biortech.2012.03.055.

- Peruzzo N. y Rodríguez Juele, A. (s.f.). Comic bacterias. Bacterias: La historia más pequeña jamás contada. Recuperado de: https://www.comicbacterias.com/.

* Qin, Y., Fu, Y., Chen, H., Liu, H., y Sun, Y. (2018). Microgravity effect on endophytic bacteria communities of Triticum aestivum. Acta Astronautica, 143, 297-301. DOI: https://doi.org/10.1016/j.actaastro.2017.11.008.

* Ruberto, L., Dias, R., Lo Balbo, A., Vazquez, S. C., Hernandez, E. A., y Mac Cormack, W. P. (2009). Influence of nutrients addition and bioaugmentation on the hydrocarbon biodegradation of a chronically contaminated Antarctic soil. Journal of applied microbiology, 106(4), 1101-1110. Dol: https://doi.org/10.1111/j.13652672.2008.04073.x.

\section{Cómo citar este artículo}

* Valdespino, Patricia M., Merino, Martín, Valdespino, Victor M. y Batista, Silvia (2019). De biofilms y otras películas. Revista Digital Universitaria (RDU). Vol. 20, núm. 5 septiembre-octubre. Dol: http://doi.org/10.22201/codeic.16076079e.2019. v20n5.a1. 